\title{
Apatite records of the magmatic- hydrothermal processes in the giant Daheishan porphyry Mo deposit, NE China
}

\author{
PAN QU ${ }^{12}$, WUBIN YANG ${ }^{1 *}$
}

${ }^{1}$ CAS Key Laboratory of Mineralogy and Metallogeny, Guangzhou Institute of Geochemistry, Chinese Academy of Sciences, Guangzhou 510640, China

${ }^{2}$ University of Chinese Academy of Sciences, Beijing 100049, China

In mineralized porphyry system, an efficient extraction and transfer of metals into hydrothermal fluids, which are exsolved from the magmas, is a key process in the formation of large porphyry deposits. Here we present comprehensively textural and compositional records of apatite from a giant porphyry Mo deposit in this study, illustrating that apatite can be a robust recorder for the magmatic-hydrothermal evolution of porphyry system. Apatite from the ore-forming Qiancuoluo granodioritic porphyry (QGP) displays a distinctive core-rim texture, showing the occurrence of dissolution-reprecipitation processes. Texturally, the observation of fluids-free melt inclusions in the resorption cores (A1 apatite) but fluid inclusions in the euhedral rims (A2 apatite) indicates that the dissolution-reprecipitation processes of apatite probably occurred in the magmatichydrothermal transitional stage. This was supported by the chemical composition that $\mathrm{A} 2$ apatite is richer in REE, $\mathrm{Y}$ and Th contents but slightly depleted in $\mathrm{Na}$ and $\mathrm{S}$ contents than the A1 apatite. Meanwhile, apatite from the Qiancuoluo biotite granodiorite (QBG), which is the wall rock of the porphyry intrusive, can also be affected by the hydrothermal processes of the porphyry system. Apatite trapped in biotite phenocrysts is usually unaltered (B1 apatite), with clear zonation in CL images. In contrast, the intergranular apatite is commonly altered (B2 apatite), with chaotic CL images, abundant micro-fractures and secondary fluid inclusions. The altered B2 apatite has a wide and high ${ }^{147} \mathrm{Sm} /{ }^{144} \mathrm{Nd}$ variable range relatively the primary $\mathrm{B} 1$ apatite, which is consistent with metasomatic modification of apatite grains led to increases of their $\mathrm{Sm} / \mathrm{Nd}$ ratios. Chemically, the altered B2 apatite shows notable tetrad REE pattern, which is enriched in HREE and depleted in LREE, compared to the unaltered B1 apatite, suggest that the B2 apatite is affected by Cl-rich hydrothermal fluids alteration. This study implies that fluid exsolution is the key factor controlling the formation of porphyry Mo deposits.

This study was supported by the National Key R\&D Program of China (2016YFC0600403). 